\title{
MECHANICAL CHARACTERIZATION OF PA 12 AND HDPE PIPES BEFORE AND AFTER AGING IN WATER AT TWO DIFFERENT TEMPERATURES
}

\author{
J.A. dos Santos 1, R.C. Tucunduva 2 (iD), J.R.M. d'Almeida ${ }^{* 1,2}$ (iD \\ ${ }^{* 1}$ Mechanical Engineering Department - State University of Rio de Janeiro, Rio de Janeiro, Brazil \\ 2 Chemical and Materials Engineering Department - Pontifícia Universidade Católica do Rio de \\ Janeiro, Rio de Janeiro, Brazil
}

DOI: https://doi.org/10.29121/granthaalayah.v9.i1.2021.2973

Article Type: Research Article

Article Citation: J.A. dos Santos, R.C. Tucunduva, and J.R.M.

d'Almeida (2021). MECHANICAL CHARACTERIZATION OF PA 12 AND HDPE PIPES BEFORE AND AFTER

AGING IN WATER AT TWO DIFFERENT TEMPERATURES. International Journal of Research GRANTHAALAYAH, 9(1), 248-256. https://doi.org/10.29121/granthaa layah.v9.i1.2021.2973

Received Date: 03 January 2021

Accepted Date: 31 January 2021

Keywords:

HDPE

PA12

Aging

Mechanical Behavior

Glass Transition Temperature

\section{ABSTRACT}

Polymer pipes are being widely used by many industrial segments. Although not affected by corrosion, the mechanical performance of these pipes can be reduced due to exposure to temperature, UV radiation and by contact with various fluids. Depending on the deterioration process, embrittlement or plasticization may occur, and the service life of the pipe can be severely reduced. In this work, the combined action of temperature and water upon the mechanical performance of polyamide 12 and highdensity polyethylene pipes is evaluated. Destructive and non-destructive techniques were used and the performance of both materials was compared. Both polymers were platicized by the effect of water. However, for high density polyethylene the effect of temperature was more relevant than for polyamide. This behavior was attributed to the dependence of the free volume with the markedly different glass transition temperature of the polymers and the temperatures of testing.

\section{INTRODUCTION}

Nowadays polymer pipes are increasingly being used to transport fluids in various industrial segments. The oil \& gas segment is, for example, one where the demand for plastic pipes has significantly increased over the past years [1]. Another segment in which the polymer tubes are widely used is the transportation and distribution of drinking water, where it is estimated that more than $69 \%$ of the system is formed by plastic tubes [2]. These pipes have as main advantages low density and resistance to corrosion. Very relevant too is the fact that the cost of assembly and maintenance of polymer pipes can be very cost effective when compared to those of steel pipes.

High density polyethylene (HDPE) and polyamide (PA) are two of the most largely used polymers used to manufacture pipes. This is due to the good set of properties these polymers possess, especially in relation to chemical stability over various chemical compounds, such as gasoline [3] and lubricant oil [4].

(C) 2021 The Author(s). This is an open access article distributed under the terms of the Creative Commons Attribution License, which permits unrestricted use, distribution, and reproduction in any medium, provided the original author and source are credited. 
However, the mechanical properties of polymers can deteriorate during their service lives due to several factors, including prolonged exposure to UV radiation, chemicals, water and temperature [5]. Combination of these factors can greatly reduce the expected service life. For example, the predicted life of polybutylene pipes designed for water transportation was severely reduced from $>50$ years to $\sim 15$ years, due to the combined effect of temperature and chlorine added to domestic water as a disinfectant [6]. In many instances, deterioration results in embrittlement of the polymer and this can be a severe issue for the performance of the polymer part or assembly [5]. When pipes are used under the ground, embrittlement can lead to crack initiation and can cause leakage of the transported fluid, for example, due to the loads caused by normal traffic on a street under which the pipe is. On the other hand, the water absorption can plasticize the polymer, which can cause excessive permanent deformation in the polymer part[7].

In this work, a study was undertaken to analyze and compare the mechanical behavior of PA12 and HDPE after exposure of these materials to water aging under different temperatures. In addition to destructive tests, the evaluation of the mechanical behavior of these polymers was also performed using non-destructive analyses.

\section{MATERIALS AND METHODS}

Commercial high-density polyethylene (HDPE) and polyamide 12 (PA12) pipes were used in this work. The nominal diameter and thickness of the pipes were, respectively, $110 \mathrm{~mm}$ and $10 \mathrm{~mm}$ for both materials. The PA12 used in this work is designed to withstand higher operating pressures and has a glass transition temperature (Tg) of $36^{\circ} \mathrm{C}$, as specified by its manufacturer. The HDPE pipe is also designed to operate pressurized and has a Tg of $110^{\circ} \mathrm{C}$.

Specimens were machined from the pipes in order to perform the mechanical tests, following the geometry and dimensions appropriate to each test. Table 1 summarizes the tests performed, the corresponding standards and also some remarks regarding specific details of the geometry of the specimens.

Table 1: Summary of the tests performed.

\begin{tabular}{|c|c|c|}
\hline Test & Standard & Remark \\
\hline Tensile & ASTM D 638 & Type I specimens, gage length of 50 mm \\
\hline Izod & ASTM D 256 & V notch specimens \\
\hline Parallel plate loading & ASTM D 2412 & Rings, 25.4 mm large \\
\hline Impulse excitation & ASTM E 1876 & Ring specimens with the same dimensions of parallel plate loading \\
& & \begin{tabular}{c} 
specimens \\
\hline
\end{tabular}
\end{tabular}

The tensile, impact and sonic test samples were aged in tap water for a period of 6 months. Part of the samples was aged at room temperature $\left(23 \pm 2^{\circ} \mathrm{C}\right)$ and part was aged at $70 \pm 1^{\circ} \mathrm{C}$. This temperature was chosen because it is close to the maximum normal working temperature of polymeric pipes. The parallel plate loading samples were aged at the same experimental conditions for a period of 7 months.

The tensile tests were performed using test equipment with a capacity of $10 \mathrm{kN}$. The test speed used was 50 $\mathrm{mm} / \mathrm{min}$ and 5 specimens were tested in the as-received condition and after 6 months of immersion in water. The objective of these tests was to evaluate the variation in the yield stress of the polymers due to aging. Thus, the tests were performed only up to a deformation of $10 \%$, beyond the yield stress. Izod impact tests were performed on an equipment with $5.4 \mathrm{~J}$ capacity. Ten samples were tested for each material condition.

The parallel plate loading test was performed on a test equipment with a capacity of $30 \mathrm{kN}$. The compressive load was applied at a constant rate of $12.5 \pm 0.5 \mathrm{~mm} / \mathrm{min}$. As recommended by ASTM standard D 2412, the test was stopped when a reduction of $40 \%$ of the original pipe diameter is achieved. Three specimens were tested for each material condition. The elastic recovery of these samples was evaluated by measuring the variation of the diameter as a function of time. Periodic measurements were carried out over 4 months. Measurements were performed using a ruler caliper with an accuracy of $0.2 \mathrm{~mm}$. For the first 10 days measurements were taken at 24-hour intervals. After this period the measurements were carried out with an interval of 10 days during 4 months. After 4 months, the variations of the measurements obtained were on the precision scale of the measuring instrument. Thus, the measurement procedure was ended. 
The impulse excitation tests were performed using an electret microphone with a detection range varying from 0.5 to $20 \mathrm{kHz}$, and an acquisition time of $0.6 \mathrm{~s}$. The signal acquired was processed by dedicated software (Sonelastic ${ }^{\circledR}$ ). The samples were first measured using a ruler caliper within $\pm 0.01 \mathrm{~mm}$ and weighted within \pm $0.0001 \mathrm{~g}$. The test configuration used is shown at Fig.1, where the relative position between the actuator (A) and the microphone (B) corresponds to the flexional-torsional boundary condition [8]. The results reported are the average of 10 measurements per specimen.

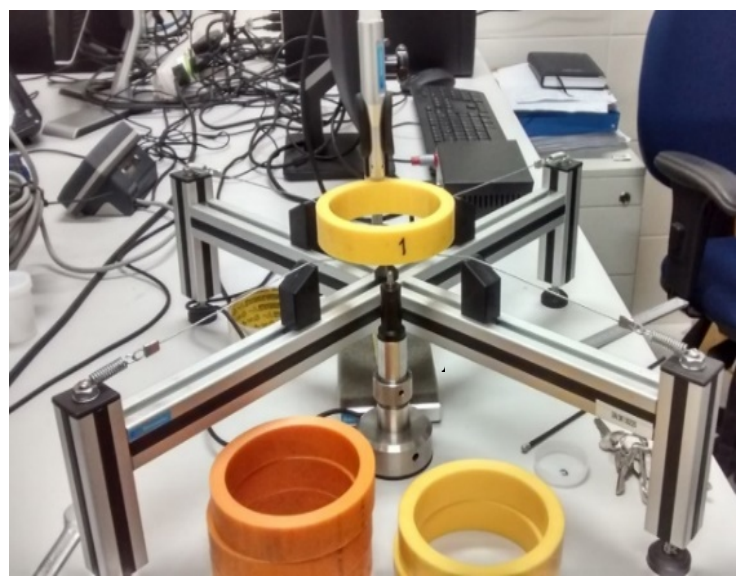

Figure 1: Test configuration of the impulse excitation tests. The actuator (A) and the microphone (B) are highlighted.

The fracture surface of the Izod specimens was analyzed by scanning electron microscopy (SEM). The analysis was performed using secondary electrons, with electron beam voltage of $20 \mathrm{kV}$ and current of $40 \mathrm{~mA}$ on gold sputtered surfaces.

\section{RESULTS AND DISCUSSIONS}

The results of the tensile tests are summarized in Table 2. Although the standard deviation of the results is high, it is possible to observe that the mean values of the yield stress are reduced and those of the yield strain are increased due to aging. For HDPE the aging at $70^{\circ} \mathrm{C}$ caused the greatest variations on yield point in relation to the as-received material. For PA 12, the effect of temperature does not seem to be as effective and the effect of water absorption seems to be more important. The percentage variation of the mean values is also presented in parentheses in Table 2.

Table 2: Yield stress and strain before and after aging at room temperature (RT) and at $70^{\circ} \mathrm{C}$.

\begin{tabular}{|c|c|c|c|}
\hline Material & As-received & Aged, RT & Aged, $70^{\circ} \mathrm{C}$ \\
\hline \multicolumn{3}{|c|}{ Yield stress (MPa) } \\
\hline HDPE & $25.5 \pm 1.2$ & $24.6 \pm 0.6(-3.7 \%)$ & $21.1 \pm 4.5(-17.2 \%)$ \\
\hline PA12 & $39.4 \pm 0.5$ & $34.9 \pm 0.6(-11.4 \%)$ & $36.9 \pm 1.1(-6.5 \%)$ \\
\hline \multicolumn{3}{|c|}{ Yield strain (\%) } \\
\hline HDPE & $12 \pm 1$ & $15 \pm 1(+25.7 \%)$ & $16 \pm 2(+35.4 \%)$ \\
\hline PA12 & $20 \pm 1$ & $24 \pm 1(+20.0 \%)$ & $24 \pm 1(+20.0 \%)$ \\
\hline
\end{tabular}

Fig. 2 shows appearance changes undergone by the HDPE due to the aging process. Fig.2a shows the as-received material. Figs. $2 \mathrm{~b}$ and $2 \mathrm{c}$ show the material aged at room temperature and at $70{ }^{\circ} \mathrm{C}$, respectively. It can be seen that the original orange and reflective surface is turning dark orange and opaque. For PA 12 the visual changes were much more subtle, and just a reduction of gloss was observed after aging.

The difference of behavior between the two polymers may be related to several factors, which affect the absorption of the fluid by the polymer, namely: i) the polarity of the polymeric chain[9]; ii) the degree of crystallinity of the polymer [10], and iii) the polymer to fluid affinity [11]. Besides, the difference between the glass transition 
temperature of each polymer and the aging temperatures can be important because it affects the free volume of the polymer [12].

In respect to the polarity of the polymer chain and its influence upon absorption of water, it is expected that polar polymers are to be more sensitive to the diffusion process than apolar polymers [9],[13]. On the other hand, in relation to the degree of crystallinity, the higher the value of the degree of crystallinity, the lower the diffusivity, because the crystalline regions are more compact than the amorphous regions. Therefore, analyzing only these aspects it would be expected that HDPE, which is a polymer with a high degree of crystallinity, would be less affected than polyamide, which in addition to lower crystallinity, is a polar polymer.
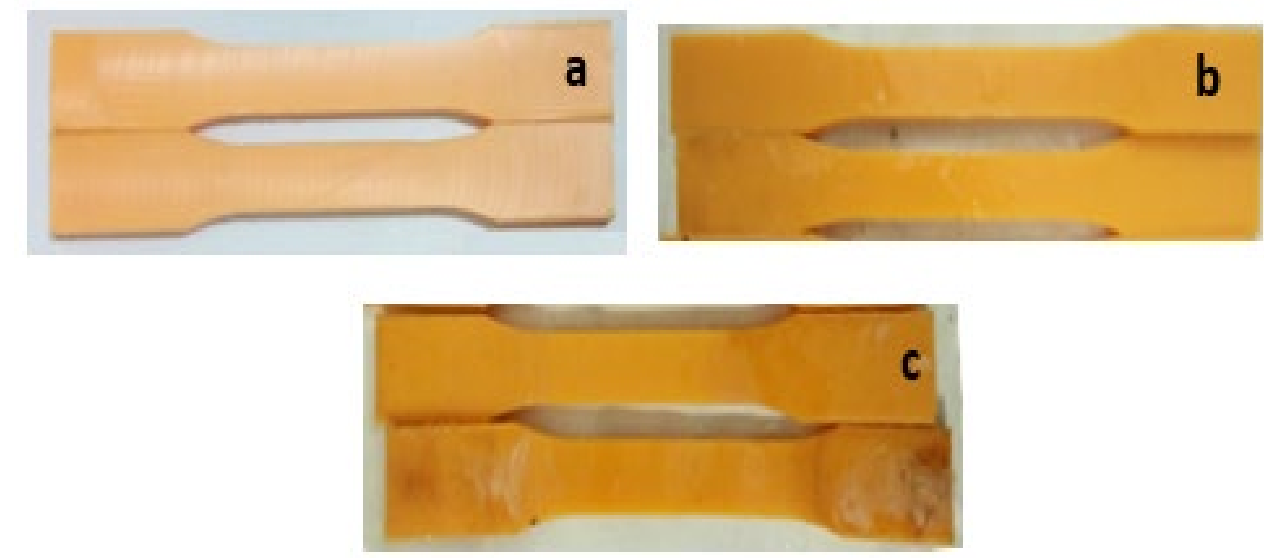

Figure 2: Variation of the aspect of HDPE tensile specimens as a function of aging: a) as-received; b): aged at room temperature; c) aged at $70^{\circ} \mathrm{C}$.

The Flory-Huggins equation can be used to infer the interaction between HDPE and PA 12 with water. Namely,

$$
\chi_{12}=\frac{V\left(\delta_{1}-\delta_{2}\right)^{2}}{R T}+\beta
$$

where $\chi_{12}$ is the interaction coefficient that indicates the affinity of a polymer with a solvent, $\mathrm{V}$ is the molar volume of the solvent, $R$ is the perfect gas constant, $T$ is the temperature $(K), \delta_{1}$ and $\delta_{2}$ are, respectively, the Hidelbrand solubility parameter of the solvent and of the polymer and $\beta$ is the entropy term $\cong 0.34)$ [11],[14]. From this equation, and using the following Hansen solubility parameters for polyethylene $\left(\delta_{2}=17.6\right)$, for polyamide $\left(\delta_{2}\right.$ $=22.8$ ) and for water $\left(\delta_{1}=47.8\right)$ [14], it can be observed that the interaction coefficient, $\chi_{12}$, for HDPE-water is higher than the polyamide-water interaction coefficient, because $\left(\delta_{2}-\delta_{1}\right)^{2}$ HDPE $>\left(\delta_{2}-\delta_{1}\right)^{2}$ PA12.

This analysis, therefore, indicates that the diffusion of water in HDPE is to be more difficult than the diffusion of the water in the polyamide, because if the difference between the parameters is small, the liquid-polymer affinity is high and the diffusion of the liquid will be favored [11].

Thus, the greater variation of the properties of the HDPE over that of the polyamide cannot be explained solely on the basis of the water / polymer affinity or the parameters of crystallinity and polarity. The relationship between the aging temperatures and the glass transition temperatures of the two polymers seems to be the main parameter to be considered. In fact, as previously mentioned, the difference between these temperatures affects the fraction of the free volume.

The glass transition temperature of the polyamide $\left(35^{\circ} \mathrm{C}\right.$ to $\left.45^{\circ} \mathrm{C}\right)$ is near the aging temperatures, while the $\mathrm{Tg}$ of the polyethylene $\left(-110^{\circ} \mathrm{C}\right)$ is well below both temperatures (i.e., 23 and $70^{\circ} \mathrm{C}$ ). As the free-volume fraction is proportional to $\mathrm{T}-\mathrm{Tg}$, the free volume available for water diffusion in HDPE will be greater than in the polyamide [11]. This may result in a higher plasticizing effect when aging occurs at $70^{\circ} \mathrm{C}$ than at room temperature for $\mathrm{HDPE}$, but not for PA. Therefore, the temperature had a much greater relevance for HDPE than for PA, including the variation of the visual appearance of the samples.

The results of the Izod impact test are shown in Fig.3. These results are in agreement with the trend observed in the tensile test, i.e., the temperature plays an important role for the aging of HDPE, but not in relation to the PA. 


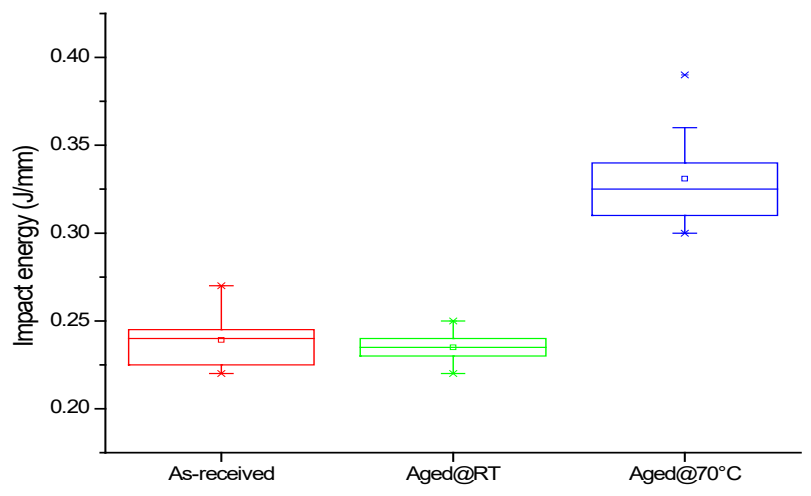

(a)

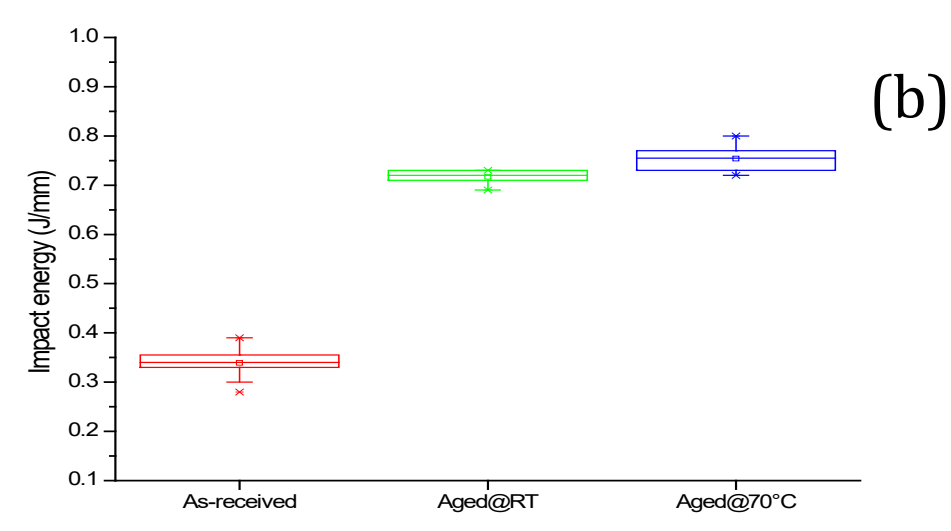

Figure 3: Izod test: a) HDPE; b) PA12.

The overall trend of the results of the impact tests also agrees with the observation that the material is being plasticized by water, as expected. Therefore, the impact energy increases after aging, with the exception of the HDPE samples aged at room temperature. SEM fractographic analysis of the samples corroborates the increase of impact strength after aging. The fracture surface of the as-received specimens shows the usual pattern of mirror, mist and hackle regions common to polymers, Fig.4a [15],[17].
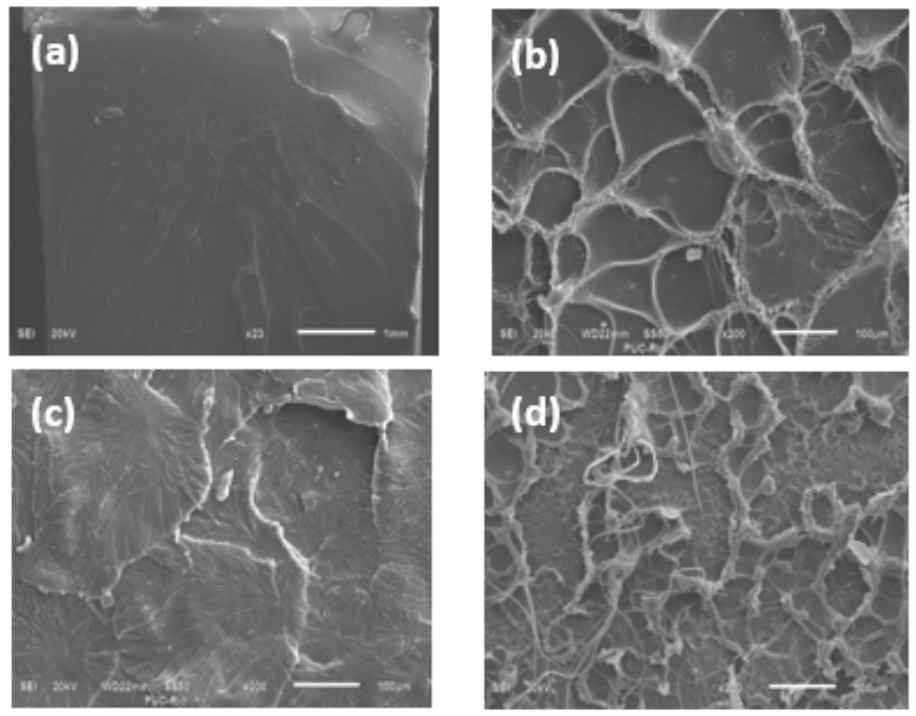


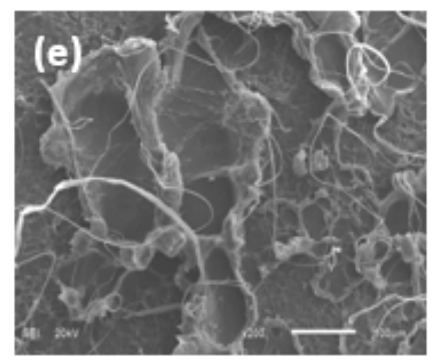

Figure 4: Fracture surface of the impact specimens: (a) Overall view, showing the common mirror, mist and hackle regions (HDPE, 23x); (b) Characteristic features of the mist to hackle transition region (HDPE, 200x); (c) Idem (PA, 200x); (d) After aging long striae are present at the mist to hackle region (HDPE, 200x); (e) Idem (PA, 200x).

At the mist to hackle transition, incipient striae can be observed, Figs. 4b and 4c, indicating a certain degree of plastic deformation capacity [18]. However, after aging very long striae are observed, Figs.4d and 4e, and, since striae are formed by shear and are indicative of deformation processes in the polymer [18], their presence is indicative that the deformability of the polymers was increased due to water absorption. It should be noted, however, that with the SEM analysis, it was not possible to see differences between the striae formed after aging at room temperature and $70^{\circ} \mathrm{C}$.

As stated by ASTM D 2412-08 standard, the parallel plate test has as its prime result the absence of cracks at the surface of the pipe, at the point where the tensile stress is at its maximum. None of the samples showed cracks, as exemplified in Fig.5. The trace of the load-elongation curves of the parallel plate loading test are shown in Fig.6. For PA12 (Fig.6a), the test results show that the curves of the as-received samples fall above the curve of the samples aged at room temperature and at $70^{\circ} \mathrm{C}$. This result agrees with the plasticizing effect of water and emphasizes that, for the same applied load, the aged samples will present larger deformation than the as-received material.

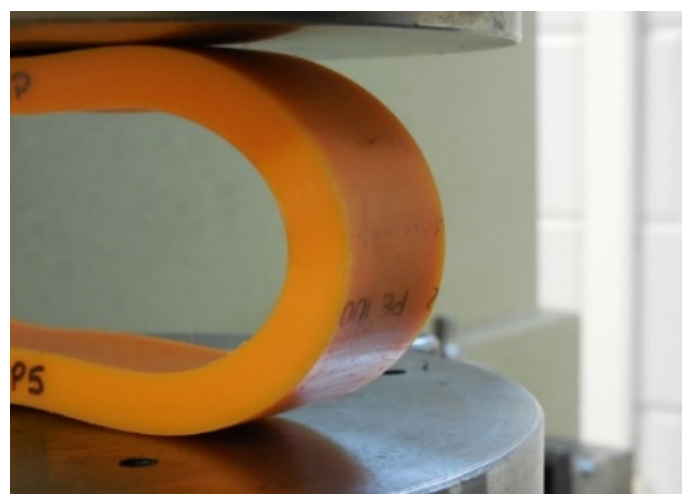

Figure 5: Naked eye inspection of the tensile surface at the parallel plate load test.
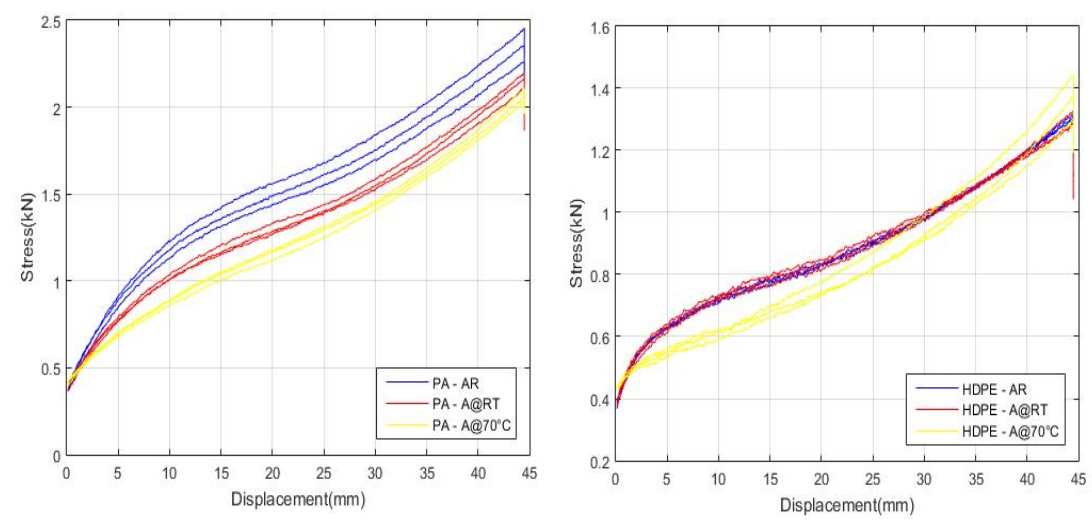

Figure 6: Parallel-plate test results for: a) PA; b) HDPE. 
However, and unlike what was observed in the tensile and impact results, the samples aged at $70{ }^{\circ} \mathrm{C}$ were more affected than those aged at room temperature. This can be clearly seen in Table 3, which lists the stiffness factor, $S F$, calculated according to equation 2, described in ASTM D 2412-08 standard, namely:

$$
S F=\frac{0.149 r^{3 F} / x}{\Delta y}(\mathrm{~N} . \mathrm{m})
$$

Where $F / x$ is the force per unit length of the pipe, $\Delta y$ is the deflection at a reduction of $40 \%$ of the original pipe diameter, and $r$ is the mean radius of the pipe.

For HDPE, as can be observed in Fig.6b, the results of the as-received samples and those aged at room temperature are almost identical. The results of these two samples fall above the curve of samples aged at $70{ }^{\circ} \mathrm{C}$, indicating, again, that temperature affects HDPE more severely than PA. The variation of the stiffness factor for the HDPE is also listed in Table 3.

Table 3: Parallel plate test: Stiffness factor $(S F)$ at $40 \%$ reduction of the original pipe diameter.

\begin{tabular}{|c|c|c|c|}
\hline & \multicolumn{3}{|c|}{$S F($ N.m) } \\
\hline & As-received & Aged, RT & Aged, $70^{\circ} \mathrm{C}$ \\
\hline PA & 38.9 & 35.5 & 34.0 \\
\hline HDPE & 21.6 & 21.4 & 22.6 \\
\hline
\end{tabular}

From a practical point of view, as important as the resistance of a polymer pipe to a crushing load is its ability to recover its original shape after load removal. This will involve, for example, resuming fluid flow without considerable energy loss. Fig.7 shows the measured elastic recovery for the HDPE and PA 12 tubes after removal of the crushing load. It is worth remembering that the diameter of the specimens was reduced by $40 \%$ during the application of the load. For both materials it is possible to see that there is a large instantaneous recovery, greater than $80 \%$, once the load is removed. After 3,300 h (140 days) the recovery of the original diameter of the PA 12 samples was about $94 \%$ and for HDPE was about $96 \%$. In fact, for both materials the elastic recovery stabilized after $\sim 500 \mathrm{~h}$.

For PA 12 there was no statistically significant difference between the elastic recovery of the samples asreceived and the aged ones (based on the results of unicaudal $t$-Student test with $95 \%$ confidence level). For HDPE the elastic recovery curves of the samples as-received and those aged at room temperature were similar. The curve for the samples aged at $70^{\circ} \mathrm{C}$ presents a slightly lower elastic recovery, in agreement with the previous results indicating that temperature had the most significant effect on the HDPE. It should be emphasized, however, that the differences obtained are not statistically different, based on Student's $t$ test results.
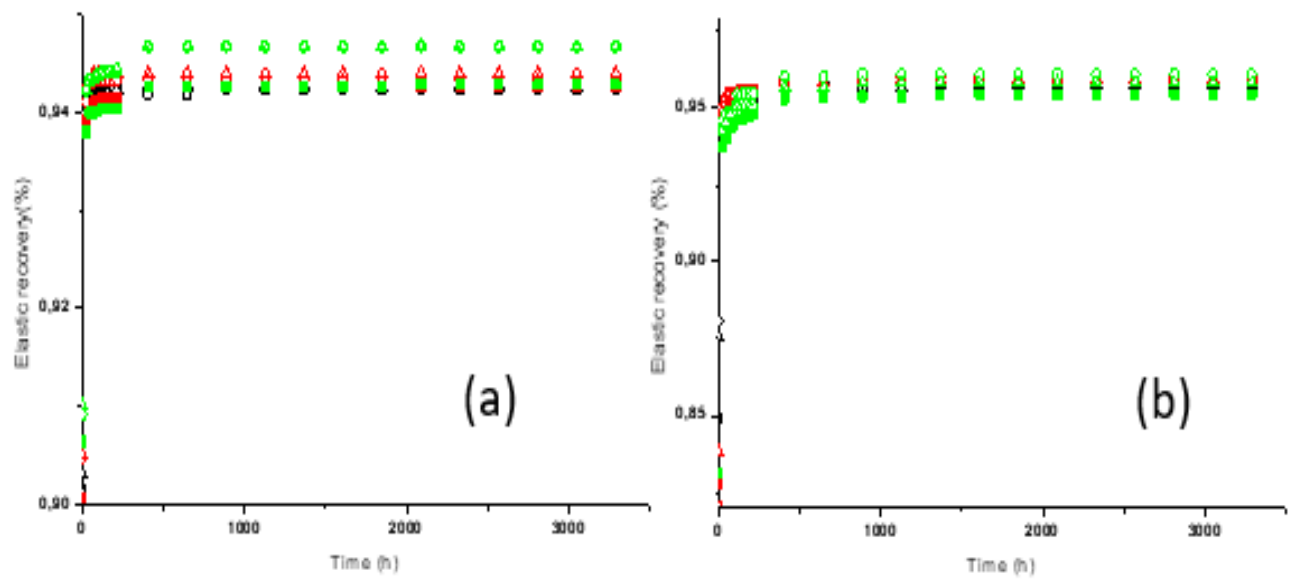

Figure 7: Elastic recovery after reduction of the diameter of the specimens by $40 \%$, and removal of the applied load. a) PA; b) HDPE. For a better visualization different symbols were used at each aging condition ( $\square, \Delta$, O). The color indicates a common aging condition. 
The results of the impulse excitation test showed that the modulus of elasticity decreased after aging. This behavior also agrees with the data so far presented, and indicates that both materials are affected by their contact with water. However, as already observed PA12 is less affected than HDPE. For the PA12, the modulus of elasticity variation was of $-4.8 \%$ and $-9.0 \%$, respectively, after aging at room temperature and at $70^{\circ} \mathrm{C}$. When $\mathrm{HDPE}$ is considered an increase of $2.0 \%$ was measured when the specimens were aged at room temperature and a decrease of $-35.0 \%$ after aging at $70^{\circ} \mathrm{C}$. The results obtained is shown in Fig.8.

The results of the impulse excitation test showed that the modulus of elasticity decreased after aging. This behavior also agrees with the data so far presented, and indicates that both materials are affected by their contact with water. However, as already observed PA12 is less affected than HDPE. For the PA12, the modulus of elasticity variation was of $-4.8 \%$ and $-9.0 \%$, respectively, after aging at room temperature and at $70^{\circ} \mathrm{C}$. When $\mathrm{HDPE}$ is considered an increase of $2.0 \%$ was measured when the specimens were aged at room temperature and a decrease of $-35.0 \%$ after aging at $70^{\circ} \mathrm{C}$. The variation of the results obtained is shown in Fig.8.

\section{CONCLUSIONS AND RECOMMENDATIONS}

The objective of this study was to evaluate the effects of exposure to water and temperature on PA12 and HDPE pipes. The results indicate that, as expected, water acts as a plasticizer and that the temperature accelerates the degradation process. Therefore, the samples aged at $70^{\circ} \mathrm{C}$ showed a greater variation of properties.

It was shown that the greater variation of the properties of HDPE in respect to that of PA12 cannot be explained solely on the basis of the water/polymer affinity or the parameters of crystallinity and polarity. In fact, water diffusion into a polymer is dependent on the free volume of the polymer, which increases with increasing temperature, but it is also dependent on the glass transition temperature of each polymer. Thus, the effect caused by aging at $70^{\circ} \mathrm{C}$ on HDPE was more pronounced than that on PA12, and the difference of behavior between PA12 and HDPE in respect to the different destructive and non-destructive test results was explained based not only on the aging test conditions but on the difference between the glass transition temperature of each polymer and the test temperatures.

The very high elastic recovery showed by the two polymers indicate that under the experimental conditions of this work, physical aging due to diffusion of water is probably the main degradation mechanism. From a practical point of view this implies that after removal of the external load the pipes almost recover their original shape, and fluid flow can be resumed without significant energy loss.

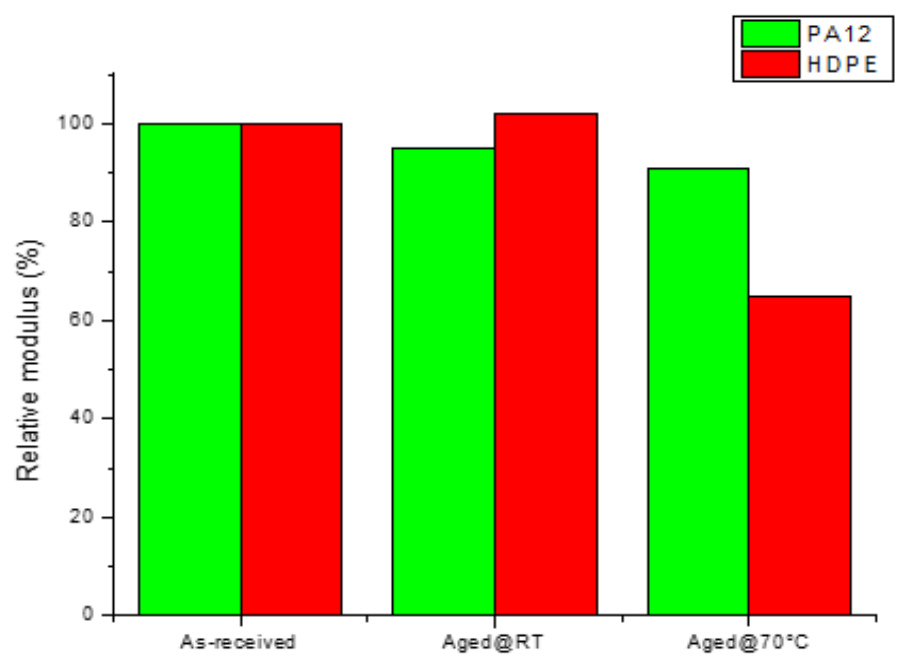

Figure 8: Variation of the elastic modulus of the aged specimens relative to the as-received materials

\section{SOURCES OF FUNDING}

This research received no specific grant from any funding agency in the public, commercial, or not-for-profit sectors.

International Journal of Research -GRANTHAALAYAH 


\section{CONFLICT OF INTEREST}

The author have declared that no competing interests exist.

\section{ACKNOWLEDGMENT}

The authors acknowledge the Brazilian Agencies CNPq (Grant number: 307363/2018-0) and CAPES (Finance Code 001).

\section{REFERENCES}

[1] Radoszewski T. Plastic Pipe - Where Past Is Prelude, Pipeline \& Gas Journal 241 (12), 2014. Available at https://pgjonline.com/2014/12/17/plastic-pipe-where-past-is-prelude/

[2] Walter RK, Lin P-H, Edwards M, Richardson RE. Investigation of factors affecting the accumulation of vinyl chloride in polyvinyl chloride piping used in drinking water distribution systems, Water Research, 45, 2011, 2607-2615.

[3] Mark JE. Polymer Data Handbook, 1st edition. Oxford: Oxford University Press; 1999.

[4] Hernández JLM, d'Almeida JRM. Aging of polyamide 12 in oil at different temperatures and pressures, Polymers for Advanced Technology, 28, 2017, 1778-1786.

[5] Wright D. Failure of Plastics and Rubber Products - Causes, Effects and Case Studies Involving Degradation, 1st edition. Shrewsbury: Rapra Technology Limited; 2001.

[6] Zhou ZW, Chudnovsky A, Niu X, Stivala SS. Failure of polybutylene pipes in potable water applications. Case study. Proceedings of Antec 96, Volume III, Conference Proceedings, Indianapolis, 1996, p.3265-3269.

[7] Zhou J, Lucas JP. Hygrothermal effects of epoxy resin. Part I: the nature of water in epoxy, Polymer, 40, 1999, 5505-5512.

[8] de Silva CW. Vibration damping, control and design. Boca Raton: Taylor \& Francis; 2007.

[9] Bouvet G, Dang N, Cohendoz S, Feaugas X, Mallarino S, Touzain S. Impact of polar groups concentration and free volume on water sorption in model epoxy free films and coatings, Progress in Organic Coatings, 96, 2016, $32-41$.

[10] Sammon C, Yarwood J, Everall N. A FTIR-ATR study of liquid diffusion processes in PET films: comparison of water with simple alcohols, Polymer, 41, 2000, 2521-2534.

[11] Ebewele RO. Polymer Science and Technology. Boca Raton: CRC Press; 2000.

[12] Hancock BC, Zografi G. The relationship between the glass transition temperature and the water content of amorphous pharmaceutical solids, Pharmaceutical Research, 11, 1994, 471-477.

[13] Gobel R, Krska R, Kellner R, Seitz RW, Tomellini SA. Investigation of Different Polymers as Coating Materials for IR/ATR Spectroscopic Trace Analysis of Chlorinated Hydrocarbons in Water, Applied Spectroscopy, 48, 1994, 678-683.

[14] Hansen CM. Hansen Solubility Parameters: a User's Handbook, 2nd edition. Boca Raton: CRC Press; 2007.

[15] Doyle MJ, Maranci A, Orowan E, Strok ST. The fracture of glassy polymers, Proceedings of the Royal Society London A, 329, 1972, 137-151.

[16] Lu X, Wang X, Brown N. Slow fracture in a homopolymer and copolymer of polyethylene, Journal of Materials Science, 14, 1988, 643-648.

[17] Rabinovitch A, Belizovsky G. Origin of mist and hackle patterns in brittle fracture, Physical Review B, 61, 2000, 14968-14973.

[18] Atsuta M, Turner DT. Fractography of highly crosslinked polymers, Journal of Materials Science Letters, 1, 1982, 167-169. 